\title{
Elastic Modulus FEM Modelling of the Layered Woven Composite Material
}

\author{
Pavla Vozkova \\ Technical University of Liberec, Faculty of Textile Engineering \\ Czech Republic
}

\section{Introduction}

Composites are top materials used for special applications. In place of traditional material, e.g. steel, the composites lower its weigh much more than the traditional material. It is based on low weight of a composite itself, on specific properties of the components and on creation possibility of composite with a specific use. The combination of the materials provides specific properties of a final composite, e.g. chemical resistance, electric and thermo-insulate properties.

The basis of a fibre reinforcing is the fact that fibres have got strength and stiffness much higher than polymer matrix. Fibres are deformed less than matrix during tensile load applied from outer power. Adhesion between components allows to distributing tension from matrix to each of all fibres.

Nowadays it is the denoted composites using, which makes possible to satisfy high requirements for special mechanical applications. Effective development is practicable only when an innovation and a construction of new composite products are set in the production - market will be developed, economical aspects will be taken into account, productivity and quality will be watched carefully, safety and ecology will be raised. Material evolution, construction principles, non-destructive testing, modelling and prediction have to be innovating and develop for materials, technology and complex system of composite materials.

The testing without a plastic deformation is not only a detection of present defects but by scanning of mechanical vibrations it is also possible to evaluate elastic constants. An alternative method for determining properties of future composite construction is a calculation with commercial software which allows corrections of equations and defining of special coefficients. The finite element method is in a use and is proved by wide science population.

The composite modelling is also an important part of the research. A visualisation of structure inside composite is necessary for an evaluation of composite properties. The structure modelling in multi-scale supports calculation in finite element method effectively. Nowadays composites are top in the aircraft industry, automotive industry and water craft construction. Building of chemical and energetic machines and construction of manufacturing machines used composites more and more in these days.

This chapter targets the study of elastic properties of carbon/carbon composites with woven 
reinforcement prepared by the prepreg technology. A simulation is based on the multi-scale modelling as a structure defining. Comsol Multiphysics ${ }^{\mathrm{TM}}$ is a tool for a finite element modelling and it is possible to solve partial differential equations. An experimental measurement is compared with a simulation for a validation of results. A non-destructive testing of resonant frequencies based on an excitation of mechanical frequencies is used for an evaluation of elastic modules in the experiment. The Hooke's law is valid during the experimental work.

\subsection{Textile reinforced composites}

Composite consists of two or more structural components. Their cooperation in the system evokes synergy - it means that properties of the end product are better than sum of component's properties only. Non-continuous components are fibres which carry the load. Continuous component is matrix and it fills surrounding around fibres. Fibres have to be the firm and high modulus. The most important property of matrix is a good adhesion to the fibre surface (Agarwal \& Broutman, 1987).

Fibres and matrix are prepared from various kinds of materials according to the application. Carbon for fibres and also for matrix is a top application for the space industry. Material has got a high tenacity, fracture toughness, high-temperature resistance, good thermal, chemical and electrical conductivity and it is easy to influence the anisotropy. Some problems with degradation in oxygen atmosphere can occur there (Savage, 1993), (Berthelot, 1999).

Composites with textile reinforcement have got good resistance against to progression of cracks. Fabric is a bidirectional layer which gives good tensile properties in warp and weft directions. The structure modelling of carbon/carbon composites is a complex problem. Here there is a irregularly crimped textile reinforcement with various inherent defects (pores, bubbles and cracks) which has risen during pyrolysis process of polymer precursor in carbon matrix. Different shrinkage during cooling plays its role too (Savage, 1993), (Fitzer \& Manocha, 1998). It is difficult to include all aspects of this complex structure to one model. The idealisation is based on geometric models as the bricks or sinusoidal curve of woven reinforcement (Bogdanowich \& Pastore, 1996), (Lomov, 2007). But results are different from experiments (Lomov et al., 2001). The description of woven interlace is very hard to study nowadays. Carbon/carbon composite with a plain weave reinforcement structure was studied by image analysis at the Technical University of Liberec. The porosity was included from $20 \%-25 \%$ in the structure (Tomkova, 2006). On the image a multi-scale geometric model of the composite structure applied in following properties simulation analysis was based (Vozkova, 2007).

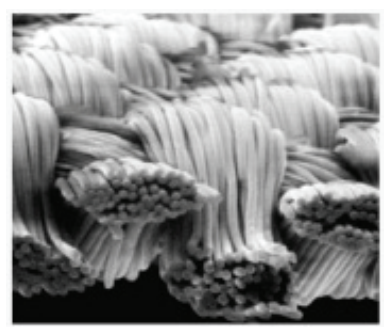

Figure 1. Plain weave of infinite fibre bundle as a possible reinforcement (Kuhn, 2007) 


\section{Composite modelling based on geometric models with finite elements}

A complex structure of the composite has to be adapted for computing. Some levels of a structure idealisation are used from simple brick models and weave idealisation to complex multi-scales. The finite element method is than used for calculation among others (Discrete Fourier transformation and different algorithms) (D'Amato, 2001), (Reddy, 2006). The finite element method is a numerical tool for a simulation process of stress, strain, heat flow and more for physical model. A continuous area is discretized to the countable number of units. It is possible to apply the simulation for a long-term testing and for a detection of critically loaded area (Hokr, 2006). Tested area is covered with the net of triangles or quadrangles that cover surface without overlapping. Loadings in the sample body are transferred to the equivalent loadings in the net structure. Each element is taken as an independent area with some boundary conditions (Reddy, 2006).

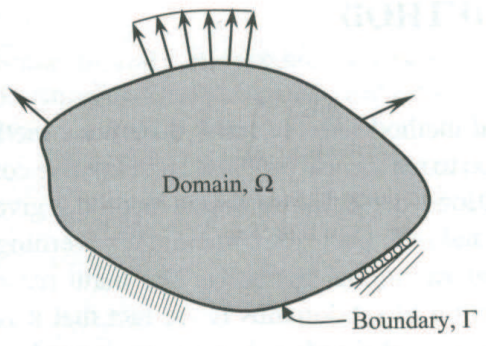

(a)

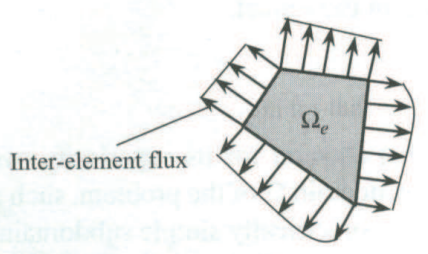

(c)

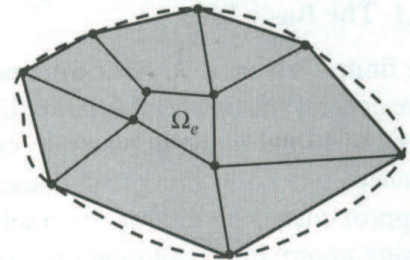

(b)

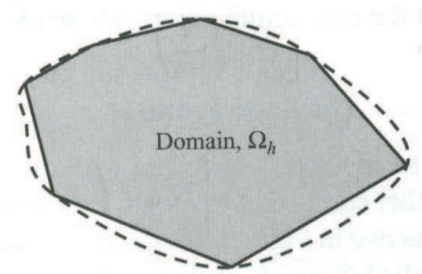

(d)

Figure 2. Representation of a two-dimensional domain by a collection of triangles and quadrangles (Reddy, 2006)

(a) geometrical complex domain, (b) collection of geometrically simple subdomains,

(c) finite element as an independent subdomain, (d) assembled relations from all elements

Subchapters contain description of model characterisation, original work from other authors about multi-scale modelling and introduction of two-dimension model for simulation use.

\subsection{Basics of the geometric models}

The volume element of a structure exists as a representative of the mechanical response for the whole composite body as an assumption. The representative volume element (RVE) is based on the type of reinforcement and on the scale. Fibres and matrix are always included in the representative volume element. A stiffness and compliance tensor describes the 
representative volume element with a mean stress and a mean strain in the volume element of the material (Berthelot, 1999).

One dimension reinforced composites, e.g. reinforced with parallel fibres which should be defined by an iso-strain model (Fig. 3.). For the model in multi-component system in loading strain of all components it is the same but there is no stress. The stiffness tensor $C_{s}$ for system with $n$ components is

$$
C_{s}=\sum_{i=1}^{n} k_{i} C_{i}
$$

where $C_{i}$ is the stiffness tensor of $i$ component and $k_{i}$ is the volume ratio of this component. Model of iso-stress (Fig. 4.) has got the same stress for all components as an assumption but there is no strain. The compliance tensor $S_{s}$ for this model should be

$$
S_{s}=\sum_{i=1}^{n} k_{i} S_{i}
$$

The compliance tensor is inverse for the stiffness tensor. Both models are on the highest and on the lowest limits for elastic properties of the composites. Both models are also applied straight to the laminate with longitudinal infinite fibres (Bogdanowich \& Pastore, 1996).

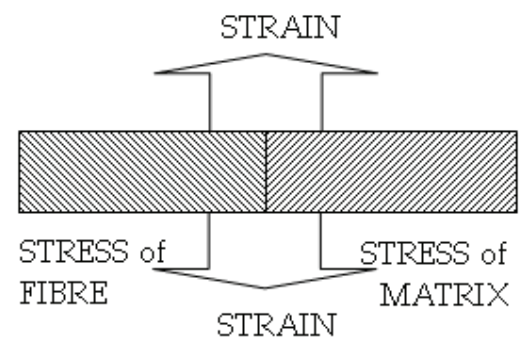

Figure 3. Model iso-strain (Tomkova, 2005)

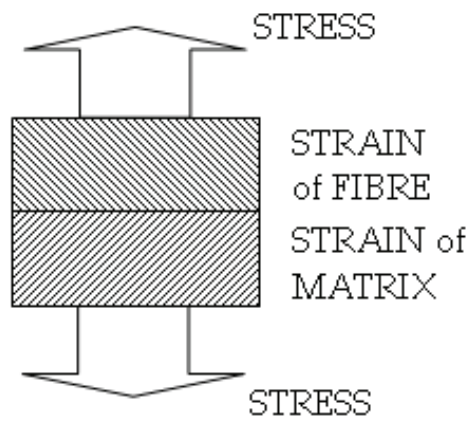

Figure 4. Model iso-stress (Tomkova, 2005)

Non-homogenous material is replaced by homogenous for the Hooke's law in mechanics of continuum. Basically is valid that the stress $\sigma_{i j}$ and the strain $\varepsilon_{i j}$ from each component with volume ratio are sums for total stress and strain according to 


$$
\begin{aligned}
& {\left[\sigma_{i j}\right]=\sum_{n} V_{n}\left[\sigma_{i j}^{n}\right]} \\
& {\left[\varepsilon_{i j}\right]=\sum_{n} V_{n}\left[\varepsilon_{i j}^{n}\right]}
\end{aligned}
$$

where $V_{n}$ is the volume ratio of each component. From the tensors stress $\sigma_{i j}$ and the strain $\varepsilon_{i j}$ it is possible to count array of stiffness $C_{i j k l}$

$$
\left[\sigma_{i j}\right]=\left[C_{i j k l}\right]\left[\varepsilon_{k l}\right]
$$

Modules of elasticity are defined in this array. Inverse to stiffness array is compliance array with coefficients of deformation. Both arrays are tensors of the fourth grade (Miravete, 2000), (Vinson \& Chou, 1975). Matrix material is pressumpted isotropic and homogenous with a structure close to vitreous carbon (Marvalova, 2000). Elastic constants are not changed during rotation around axes. Pores properties are also isotropic and do not accept gas compression (Berthelot, 1999). Reinforcement is a homogenous and transversely isotropic material. In one axis direction the properties are the same in all cases. The cross to the fibre axis is plane (Berthelot, 1999), (Stříž, 2002).

Composite from laminas is an orthotropic material with three axes of symmetry, i.e. warp, weft and cross to fabric. Stiffness array is than

$$
\left[\begin{array}{l}
\sigma_{1} \\
\sigma_{2} \\
\sigma_{3} \\
\sigma_{4} \\
\sigma_{5} \\
\sigma_{6}
\end{array}\right]=\left[\begin{array}{cccccc}
c_{11} & c_{12} & c_{13} & 0 & 0 & 0 \\
c_{12} & c_{22} & c_{23} & 0 & 0 & 0 \\
c_{13} & c_{23} & c_{33} & 0 & 0 & 0 \\
0 & 0 & 0 & c_{44} & 0 & 0 \\
0 & 0 & 0 & 0 & c_{55} & 0 \\
0 & 0 & 0 & 0 & 0 & c_{66}
\end{array}\right]\left[\begin{array}{c}
\varepsilon_{1} \\
\varepsilon_{2} \\
\varepsilon_{3} \\
\varepsilon_{4} \\
\varepsilon_{5} \\
\varepsilon_{6}
\end{array}\right]
$$

and the compliance array is

$$
\left[\begin{array}{l}
\varepsilon_{1} \\
\varepsilon_{2} \\
\varepsilon_{3} \\
\varepsilon_{4} \\
\varepsilon_{5} \\
\varepsilon_{6}
\end{array}\right]=\left[\begin{array}{cccccc}
s_{11} & s_{12} & s_{13} & 0 & 0 & 0 \\
s_{12} & s_{22} & s_{23} & 0 & 0 & 0 \\
s_{13} & s_{23} & s_{33} & 0 & 0 & 0 \\
0 & 0 & 0 & s_{44} & 0 & 0 \\
0 & 0 & 0 & 0 & s_{55} & 0 \\
0 & 0 & 0 & 0 & 0 & s_{66}
\end{array}\right]\left[\begin{array}{l}
\sigma_{1} \\
\sigma_{2} \\
\sigma_{3} \\
\sigma_{4} \\
\sigma_{5} \\
\sigma_{6}
\end{array}\right]
$$

Nine independent constants are necessary to find (Berthelot, 1999).

The compliance tensor could be found also as a relation between Young's modules, shear modules and Poisson's ratio from simplification of plain tensile test in warp direction, plain tensile test in weft direction and plain shear test from (Berthelot, 1999), (Laš, 2004) as 


$$
S=\left[\begin{array}{cccccc}
\frac{1}{E_{1}} & -\frac{\mu_{12}}{E_{1}} & -\frac{\mu_{13}}{E_{1}} & 0 & 0 & 0 \\
-\frac{\mu_{12}}{E_{1}} & \frac{1}{E_{2}} & -\frac{\mu_{23}}{E_{2}} & 0 & 0 & 0 \\
-\frac{\mu_{13}}{E_{1}} & -\frac{\mu_{23}}{E_{2}} & \frac{1}{E_{3}} & 0 & 0 & 0 \\
0 & 0 & 0 & \frac{1}{G_{23}} & 0 & 0 \\
0 & 0 & 0 & 0 & \frac{1}{G_{13}} & 0 \\
0 & 0 & 0 & 0 & 0 & \frac{1}{G_{12}}
\end{array}\right]
$$

Loading in on axis direction has to be transferred to the symmetry axis in defined angle $\delta$ (Berthelot, 1999). Loading is than transferred to the main directions. Longitudinal modulus could be defined as

$$
\frac{1}{E_{x}}=S_{11} \cos ^{4} \delta+S_{22} \sin ^{4} \delta+\left(2 S_{12}+S_{66}\right) \cos ^{2} \delta \sin ^{2} \delta
$$

and with inclusion constants from compliance tensor

$$
\frac{1}{E_{x}}=\frac{1}{E_{L}} \cos ^{4} \delta+\frac{1}{E_{T}} \sin ^{4} \delta+\left(\frac{1}{G_{L T}}-\frac{2 \mu_{L T}}{E_{L}}\right) \cos ^{2} \delta \sin ^{2} \delta
$$

Shear modulus has got simple presumption

$$
G_{x y}=\frac{1}{S_{66}^{\prime}} \text { so } \frac{1}{G_{x y}}=2\left(\frac{2}{E_{L}}+\frac{2}{E_{T}}-\frac{1}{G_{L T}}+\frac{4 \mu_{L T}}{E_{L}}\right) \cos ^{2} \delta \sin ^{2} \delta+\frac{1}{G_{L T}}\left(\sin ^{4} \delta+\cos ^{4} \delta\right) \text {. }
$$

\subsection{Complex geometric models}

The multi-scale modelling allows decomposition of complex heterogeneous structure to the partial levels from the simplest composition to the composition of whole sample body. They are substituted from the lowest level properties to higher and also highered up to the higher studied composite structure. The accuracy of the simulation is better because specifications and properties from each scale are combined during processing. On Fig. 7. is parting to the scales (Berthelot, 1999), (Lomov et al., 2007).

Interesting research for complex geometry of the textile reinforced composites made the team of prof. Lomov from Belgium. They introduced the set of programs of a structure geometry composition, modelling of complex geometry, meshing of nets and properties calculation. On Fig. 8. is simple diagram of their work (Lomov et al., 2001), (Lomov et al., 2007). Each program is specialized for some operation and together it is possible to compute properties of some composite. 

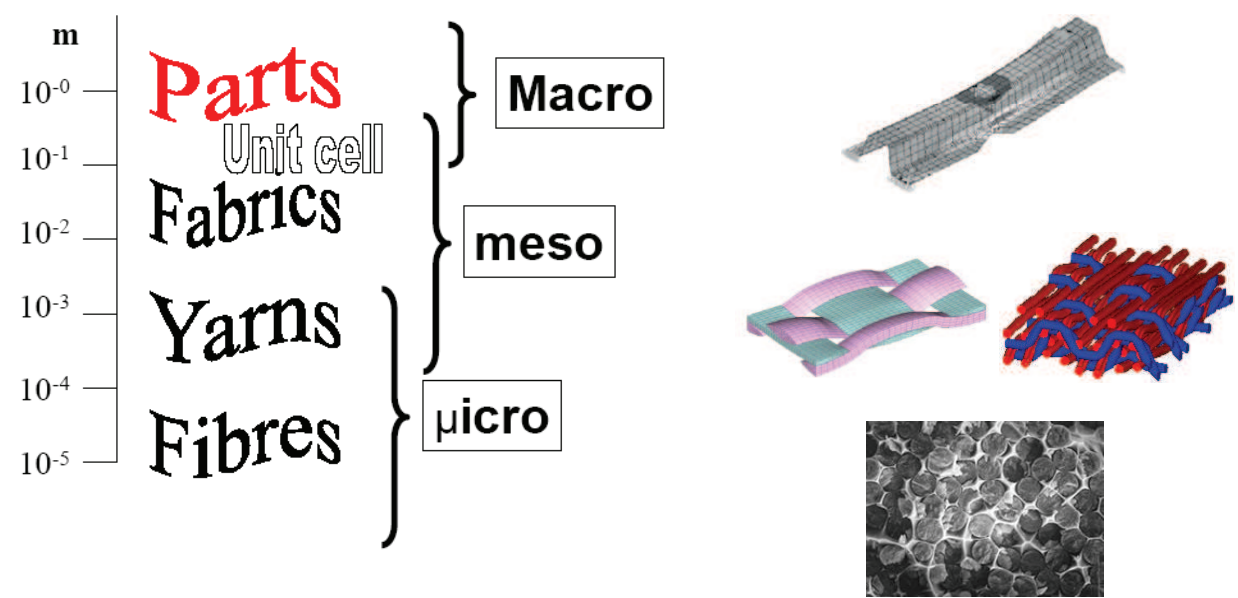

Figure 7. Scale distribution of sample geometry (Lomov et al., 2007)

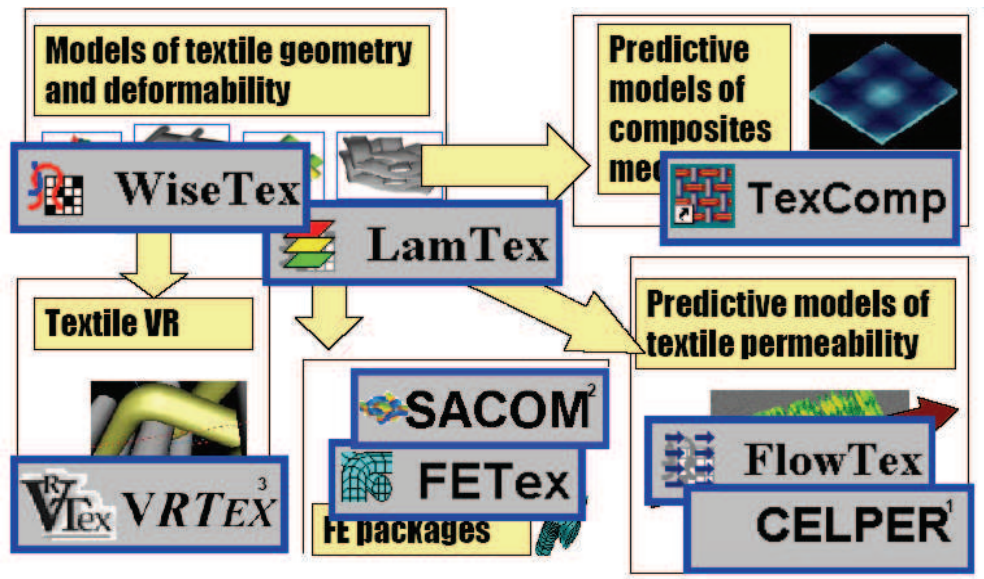

Figure 8. System for composite simulation (Lomov, 2007)

Many authors are following Lomov's team and their outputs. Mechanical or thermal properties are counted from these programs for the textile reinforced composites, tensile tests, bending, plain shear, etc. A similar way was found by the team of prof. Sejnoha from the Czech Republic. The multi-scale modelling is applied on textile composites but also on the more mechanical objects, e.g. bridges (Šejnoha, 2007), (Skoček et al., 2005).

\subsection{Multi-scale modelling for simulation}

A consideration about the structure of composites could be done from Fig. 9. A simulation in this chapter presents the two-dimensional model of lengthwise and crosswise fibre bundles surrounded with matrix. Defects are mentioned here, too. It is necessary to include defects in the bundles, between laminas and voids raised during pyrolysis and layering. Whole structure is a combination of geometry formations. 


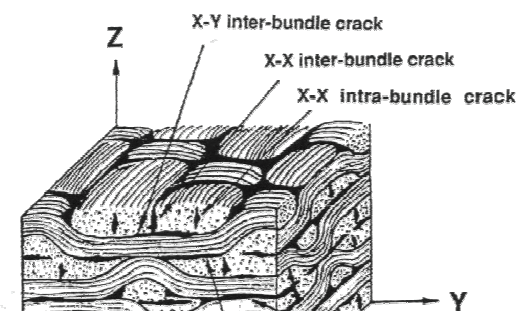




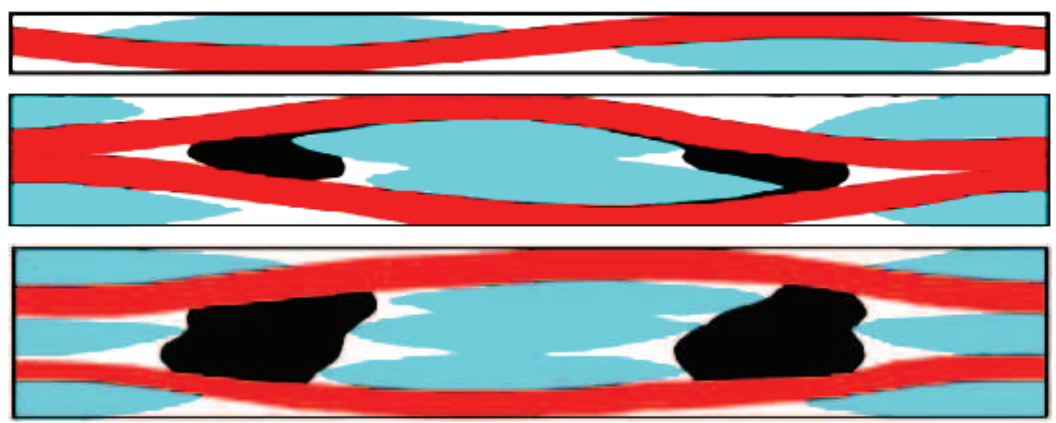

Figure 12 Structural Unit cell 1,2,3 (Tomkova, 2006) (blue - crosswise fibre bundles, red lengthwise fibre bundles, black - voids, white - matrix)

Laminas model whole composite structure on Fig. 14. In the simulation lamina and composite structure are idealized as a bricks with identical properties in each brick counted from lower scale (unit cell $\rightarrow$ lamina bricks $\rightarrow$ composite bricks) (Tomkova, 2006), (Šejnoha, 2007). Table 1 . shows sizes of all defined structure elements from multi-scale model.

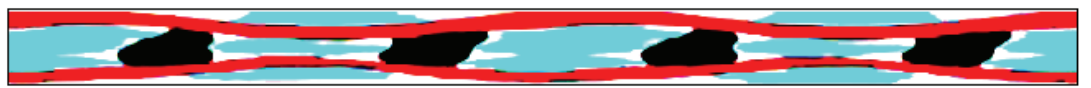

Figure 13. Structural model of Lamina (Tomkova, 2006) (blue - crosswise fibre bundles, red - lengthwise fibre bundles, black - voids, white - matrix)

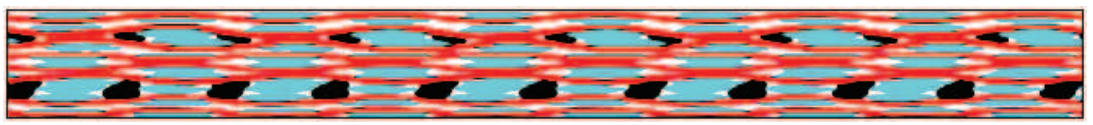

Figure 14. Whole composite structure (Tomkova, 2006) (blue - crosswise fibre bundles, red - lengthwise fibre bundles, black - voids, white - matrix)

\begin{tabular}{|c|c|c|}
\hline Scale and type of the tested sample & length [m] & high $[\mathrm{m}]$ \\
\hline Crosswise bundle section & $2,2.10^{-4}$ & $1,8.10^{-5}$ \\
\hline Lengthwise bundle section & $2,2.10^{-4}$ & $1,8.10^{-5}$ \\
\hline Crosswise bundle with defects & $1,8.10^{-3}$ & $1,8.10^{-4}$ \\
\hline Lengthwise bundle section with defects & $1,8.10^{-3}$ & $1,8.10^{-4}$ \\
\hline Structure unit cell 1 & $4,5.10^{-3}$ & $0,3 \cdot 10^{-3}$ \\
\hline Structure unit cell 2 & $4,5.10^{-3}$ & $0,5 \cdot 10^{-3}$ \\
\hline Structure unit cell 3 & $4,5.10^{-3}$ & $0,7 \cdot 10^{-3}$ \\
\hline Lamina 1 & 0,0315 & $0,3 \cdot 10^{-3}$ \\
\hline Lamina 2 & 0,0315 & $0,5.10^{-3}$ \\
\hline Lamina 3 & 0,0315 & $0,7 \cdot 10^{-3}$ \\
\hline Whole composite structure & 0,0315 & $1,5.10^{-3}$ \\
\hline
\end{tabular}

Table 1. Size of structure elements of multi-scale model for simulation 


\section{Direct testing of composites}

Destructive and non-destructive testing and its brief description are included below. An experimental and also a simulation work are based on oscillation of composite samples. Movement equations are presented here also with special experiment premises.

\subsection{Destructive testing}

The tensile testing is time and money consuming but it is widely used specially for explicit results. It includes the tensile testing to rupture, bending, pressure, cycle testing, dynamic and high loaded testing of fibres, as well as whole composites. Tested samples have to be prepared precisely before testing and special handling is also necessary (Bogdanovich \& Pastore, 1996), (Ivanov et al., 2007).

\subsection{Non-destructive testing}

The non-destructive testing is a treatment on the sample without a rise of non-reversible deformation. These tests were used for safety at first. The testing is repeatable and cheaper because a sample is not destructed. Special signal impacts the sample and response of material is detected. Detection of defects is widely used in non-destructive tests. Optical and visualisation methods scan surface of the sample with optical microscopes, magnifying glass or glasses on the unit cell level or lamination where a component boundary is clearly visible. Magnification is possible with scanning electron microscopes etc. (Introduction to NDT, 2002), (Diedericks, 2002). The penetrate method also detects volume characteristics of composite surface. It is necessary to use a penetrate liquid which is in the contact with surface, so a clear medium and nonporous structure is important (NDT encyclopedia, 2007). The magnetic inspection is possible only for ferromagnetic materials, demagnetisation ending and clear medium (Introduction to NDT, 2002).

The radiography is used for inspection through a material structure. Neutron, roentgen and gamma radiography are spread. The principle is an application of short weave lengths. An intensity of trans-illumination is detected. Places with lower density and with defects transmit more radiation than surroundings. A danger from an irradiation is the biggest problem of this method (Introduction to NDT, 2002), (La Plante et al., 2005).

An ultrasound is widely used for a defect detection, a thickness determination, a monitoring of degradation and abrasion, an impregnation ratio, a delaminating, a density, a porosity and a size of crystals. It is called a contact measurement. Weaves go through a sample and come back from the next end or from the defect. It is possible to vibrate with very thin samples (La Plante et al., 2005), (NDT encyclopedia, 2007).

A mechanical response of material is detected from various methods. The proof experimental method for obtaining mechanical properties is an evaluation of eigenfrequencies of vibration going through a composite plate. Lagrange's, Euler-Bernoulli's, Rayleigh's and Timoshenko's theories are relevant (Černý, 2000). The Lagrange's theory is valid for the longitudinal oscillation. Theory Euler-Bernoulli is basic for the transversal oscillation and Rayleigh with Timoshenko made corrections of it (Brepta et al., 1994). In (Puchegger, 2003) is valid only for isotropic material. Sample is hanged on two carbon fibre loops. These loops are connected with a piezo-electric sensor. In the sample a bending oscillation and a transversal vibration is detected. The longitudinal oscillation is used for testing of elastic properties of plane wings in (Cheby \& Hwu, 2006). Sample is clamped on 
one side and free end which is on the second side. A sensor is on the free end. A longitudinal mechanical vibration is detected. The method used here is based on the analysis of longitudinal oscillation and on transversal Timoshenko's oscillation for orthotropic material (Černý, 2000). It was tested at the Department of Structure and Mechanics of Rocks of Science Academy of the Czech Republic. Deeper description follows.

\subsection{Longitudinal vibrations theory}

A thin axially symmetry beam is an assumption. Basically, cross-sections of the beam are planar during deformation and a stress is uniformly distributed in the cross-section. Only uniaxial loading is mentioned there. Transversal movements absorb neglectable amount of energy. See Fig. 15. (Brepta et al., 1994), (Brepta, 1997).

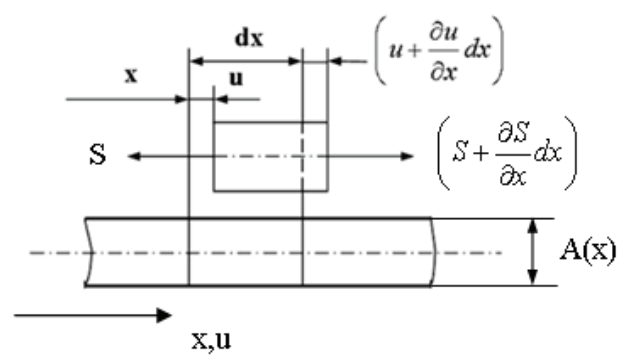

Figure 15. Deformation of thin beam evoked by longitudinal wave (Brepta et al., 1994)

The Hooke's law is valid for stress influences to the beam element for uniaxial load

$$
\sigma=E \varepsilon=E \frac{\partial u}{\partial x}
$$

where $E$ is the longitudinal tensile modulus, $\partial u / \partial x$ is the elongation same as $\varepsilon$. The motion equation is than

$$
A(x) \frac{\partial^{2} u}{\partial t^{2}}=\frac{E}{\rho} \frac{\partial}{\partial x}\left[A(x) \frac{\partial u}{x}\right]
$$

where $A$ is the cross-section area, $\rho$ is the density, $\sigma$ is the stress, $u$ is the movement in the $x$ direction, $E$ is the Young's modulus. The phase velocity of wave is defined as

$$
c_{0}^{2}=\frac{E}{\rho}
$$

and the relation has to be valid

$$
\frac{\partial u}{\partial x} \pm \frac{1}{c_{0}} \frac{\partial u}{\partial t}=k o n s t
$$

The general integral of wave equation is

$$
u(x, t)=f\left(c_{0} t+x\right)+g\left(c_{0} t-x\right)
$$


A solution is based on two waves going in the opposite directions. Relation between element velocity $v$, density $\rho$, wave velocity $c$ and stress $\sigma$ is

$$
\sigma=\rho c_{0} v=E \frac{v}{\mathrm{c}_{0}}
$$

The initial conditions for free end beam for free oscillation is that stress is at zero.

$$
E\left(\frac{\partial u}{\partial x}\right)_{x=0}=0
$$

is valid when end of the beam is on the zero of coordinates and phase is not changed (Brepta et al., 1994), (Brepta, 1997).

\subsection{Transversal vibrations theory}

The Euler-Bernoulli's theory based on an assumption that cross-sections of the beam stays planar and a deflection is made only in the cross to $x$ axis. The deflection is flat and very small anyway. Movements in $x$ direction are neglected. Loading in element $d x$ is shown on Fig. 16 (Brepta et al., 1994)

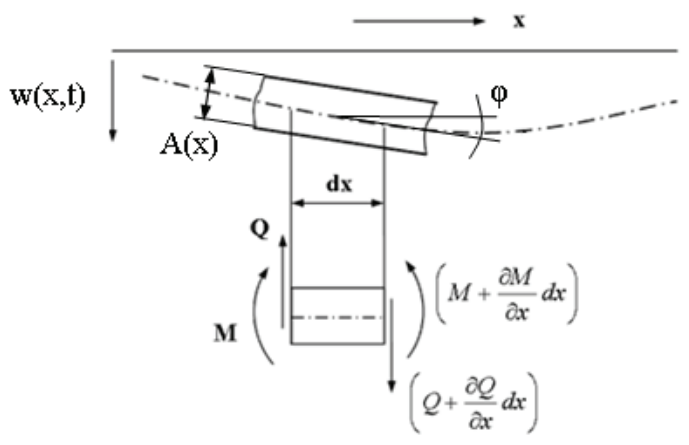

Figure 16. Loading on the element during trans oscillation (Brepta et al., 1994)

Motion equation is

$$
\rho A(x) d x \frac{\partial^{2} w}{\partial t^{2}}=\frac{\partial Q}{\partial x} d x
$$

and deflection curve for flat curves is

$$
M=-E I(x) \frac{1}{R}=-E I \frac{\partial^{2} w}{\partial x^{2}}
$$

where $E I$ is the flexural rigidity, $R$ is the radius of curvature, $w$ is the deflection. Timoshenko made corrections to basic theory. Here is neglected crimp of the cross-section. Gradient angle of the deflection curve is a sum of turn angle $\psi$ (affected by bending) and angle change $\beta$ (shear affected by displacement) 


$$
\frac{\partial w}{\partial x}=\psi+\beta
$$

Bending moment is

$$
M=-E I \frac{\partial \psi}{\partial x}
$$

where quotient is the curvature of deflection curve.

Motion equation for movement of element is

$$
A \rho \frac{\partial^{2} w}{\partial t^{2}} d x=\frac{\partial Q}{\partial x}
$$

where $Q$ is moving force. Equation for element turning is

$$
\rho I \frac{\partial^{2} \psi}{\partial t^{2}} d x=Q d x-\frac{\partial M}{\partial x} d x
$$

Movement equation for deflection $w(x, t)$ is at the end

$$
c_{0}^{2} k^{2} \frac{\partial^{4} w}{\partial x^{4}}+\frac{\partial^{2} w}{\partial t^{2}}-k^{2}\left(1+\frac{E}{G \alpha}\right) \frac{\partial^{2} w}{\partial x^{2} \partial t^{2}}+\frac{1}{\alpha} \frac{k^{2}}{c_{2}^{2}} \frac{\partial^{4} w}{\partial t^{4}}=0
$$

where $c_{2}$ is the velocity of shear waves in continuum defined $c_{2}^{2}=G / \rho$ and it is valid $E / G=2(1+\mu), \mu$ is the Poisson's ratio and $a$ is the coefficient of cross-section shape. Theory gives good results for thin beams (Brepta et al., 1994), (Brepta, 1997).

\subsection{Resonant frequency method description}

An application of the method of resonant frequencies was developed at the Department of Structure and Mechanics of Rocks of Science Academy of the Czech Republic (Černý, 2000). Than Lengthwise tensile modulus and Poisson ratio of orthotropic plate is possible to determine from resonant frequency spectrum of the longitudinal mechanical oscillation. Shear modulus is determined from a resonant spectrum of a transversal oscillation. The big advantage is accuracy of this method. The experiment is fast and absolutely non-destructive (Žaloudková, 2006).

The experiment is measured on the sensor for resonant frequency Erudite CNS Electronics Ltd., London, UK. On the exciting electrode there is brought an alternating voltage. Voltage is harmonically running with amplitude $400 \mathrm{~V}$ and exciting $10 \mathrm{~Hz}-100 \mathrm{kHz}$. Electrostatic load effects grounded conductive sample. Than electrostatic load excites mechanical oscillation. The electric current goes through the sample in the alternating voltage. So signal of a mechanic oscillation is detected on the same principle as an exciting (Černý, 2000), (Žaloudková, 2006).

It is important that axes of sample orthotropy (warp and weft of the plain weave) are positioned in the same direction as an oscillating propagation during testing. A sample has to be prepared for it. If this is not correct, propagation would be applied as a general longitudinal and transversal oscillation and explicit resonant spectrum could not be found (Černý, 2000). 


\section{Experiment}

In the experiment there is a description of the results obtained from the simulation in Comsol Multiphysics ${ }^{\mathrm{TM}}$. A deeper discussion is presented for longitudinal vibrations. The experiment is compared with a simulation and it is visualized in polar diagram for the inplane treatment in the plain weave reinforcement.

The tested composite is eight layered laminate from carbon fibre in plain weave surrounded with carbon matrix. Matrix was prepared from phenolic resin Umaform LE with hightemperature treatment. Matrix has got good size stability, thermo stability, chemical resistance and low shrinkage. Bundle is made from 6000 parallel infinite high strength carbon fibres Toray ${ }^{\circledR}$. Porosity is $20-25 \%$. Important input properties are in Table 2.

\begin{tabular}{|c|c|c|c|}
\hline Component & $\begin{array}{c}\text { Density } \\
{\left[\mathbf{k g}^{-3} \mathbf{]}\right]}\end{array}$ & $\begin{array}{c}\text { Young's modulus } \\
{[\mathbf{M P a}]}\end{array}$ & $\begin{array}{c}\text { Poisson's ratio } \\
{[-]}\end{array}$ \\
\hline Fibres Toray 800 HB & 1810 & 294000 & 0,24 \\
\hline Matrix & 1400 & 89 & 0,30 \\
\hline Voids - air & 1,3 & 0,0 & 0,0 \\
\hline
\end{tabular}

Table 2. Values of important input mechanical properties

\subsection{Simulation results}

The Structural Mechanical Module was used for computation in Comsol MultiphysicsTM 3.2. The Eigenfrequency Analysis was set as application compatible with experiment. The structure is defined at first. The properties of components, the boundaries and the external impact are defined in Physics. The help constants and equations could be defined in Options. After meshing and solving the result graphs are shown in Postprocessing.

The results for all modules are shown in Table 3. Dividing of stress and strain gives us these values as critical elastic properties. The longitudinal modulus is very different for lengthwise and crosswise bundle. The difference is smaller for bundles with defects but it is still high. The unit cell is combined from various components so the difference is minimal between unit cells. Value is in the range from previous lower scales. The laminas and the whole composites modules are at same units as unit cells. The synergy effect increases modules slowly from the unit cell to the whole composite.

The result response is defined for the first eigenfrequency of sample with free ends. One node point is detected in the middle of sample. The free ends oscillate across along the lengthwise axis. The colour scale in the figure goes from minimal dark blue through middle green to the maximal dark red for value of output property in every case. Following figures have got some geometry adaptation for better resolution and predicative possibility. Full models were described in subchapter 2.3.

The longitudinal stress of crosswise bundle is concentrated in the matrix where fibres and matrix are in the contact vertically (Fig. 17.). The lowest longitudinal stress is in the fibres in the contact with each other and matrix between them but from the scale it is clear that this stress is opposite than in matrix. The fibres are loaded with pressure. Mean stress is in the middle of the fibres. The longitudinal strain of crosswise bundle (Fig. 18.) is in the fibres and in the matrix near fibres. The pressure is in the matrix too where fibres are close together in the horizontal position. The longitudinal stress of lengthwise bundle is maximal in the matrix (Fig. 19.). The lengthwise fibres are minimal loaded in the middle but maximal at the 
ends. The longitudinal strain of lengthwise bundle (Fig. 20.) has got a maximum at the ends. The lowest strain is in the middle (in the node point of the eigenfrequency).

\begin{tabular}{|c|c|c|c|}
\hline $\begin{array}{c}\text { Scale and type of } \\
\text { the tested sample }\end{array}$ & $\begin{array}{c}\text { Longitudinal } \\
\text { modulus [MPa] } \\
\mathbf{E}_{\mathbf{x}}=\mathbf{\sigma}_{\mathbf{x}} / \boldsymbol{\varepsilon}_{\mathbf{x}}\end{array}$ & $\begin{array}{c}\text { Transversal } \\
\text { modulus [MPa] } \\
\mathbf{E}_{\mathbf{y}}=\mathbf{\sigma}_{\mathbf{y}} / \boldsymbol{\varepsilon}_{\mathbf{y}}\end{array}$ & $\begin{array}{c}\text { Shear modulus } \\
{[\mathbf{M P a}]} \\
\mathbf{G}_{\mathbf{x y}}=\mathbf{\sigma}_{\mathbf{x y}} / \varepsilon_{\mathbf{x y}}\end{array}$ \\
\hline Crosswise bundle & 252,8 & 52,9 & 103,2 \\
\hline Lengthwise bundle & 160289,0 & 97,9 & 61570,8 \\
\hline $\begin{array}{c}\text { Crosswise bundle } \\
\text { with defects }\end{array}$ & 189,6 & 129,0 & 38,6 \\
\hline $\begin{array}{c}\text { Lengthwise bundle } \\
\text { with defects }\end{array}$ & 130663,1 & 623,0 & 40005,0 \\
\hline Unit cell 1 & 54813,2 & 408,2 & 9530,1 \\
\hline Unit cell 2 & 62374,9 & 716,8 & 9267,2 \\
\hline Unit cell 3 & 53259,2 & 949,7 & 8491,5 \\
\hline Lamina 1 & 54807,5 & 534,8 & 6859,4 \\
\hline Lamina 2 & 62384,7 & 626,3 & 7607,7 \\
\hline Lamina 3 & 53245,4 & 554,1 & 6684,2 \\
\hline Whole composite & $\mathbf{8 6 2 6 4 , 1}$ & $\mathbf{6 1 7 , 2}$ & $\mathbf{7 3 4 0 , 0}$ \\
\hline
\end{tabular}

Table 3. Results from the simulation in Comsol Multiphysics

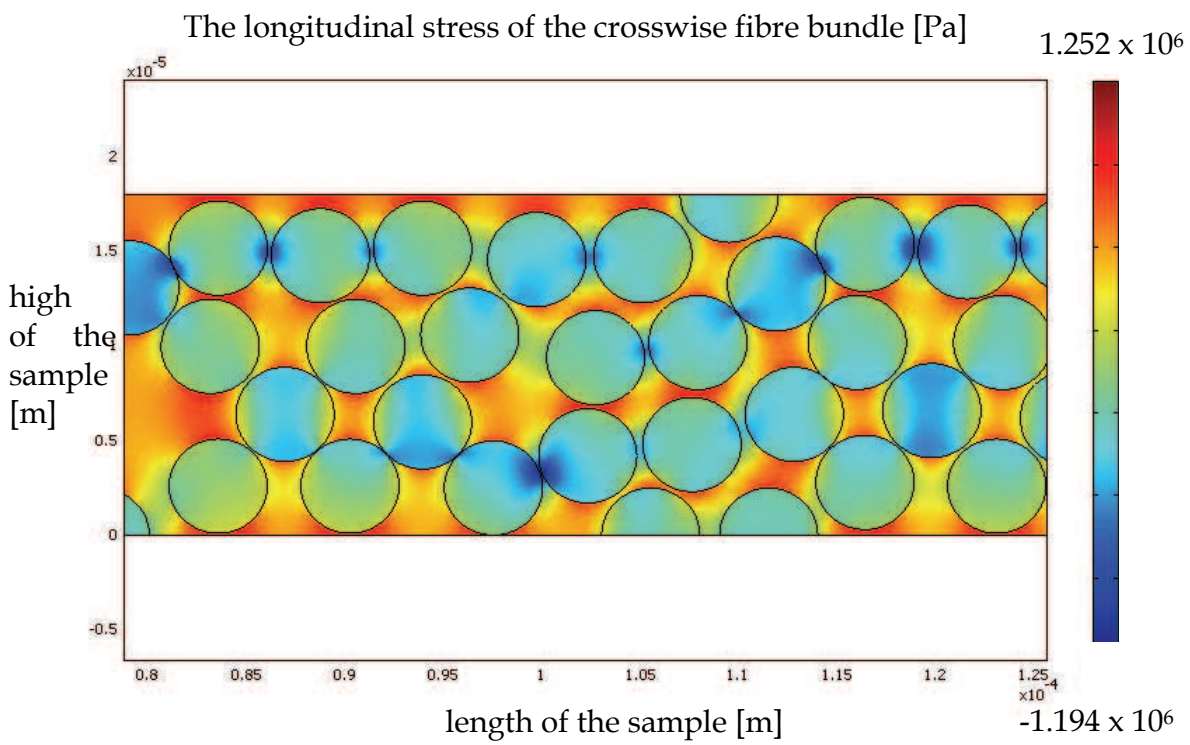

Figure 17. Longitudinal stress of the crosswise fibre bundle 
The longitudinal strain of the crosswise fibre bundle [-]

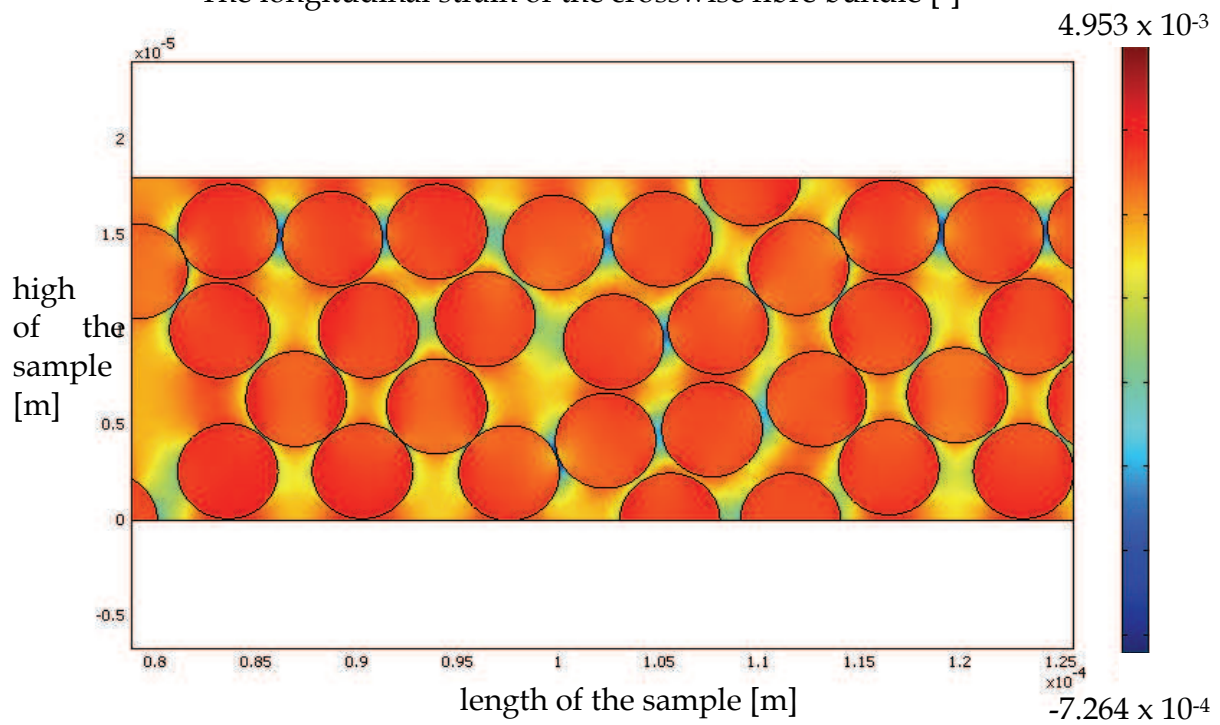

Figure 18. Longitudinal strain of the crosswise fibre bundle

The longitudinal stress of the lengthwise fibre bundle [Pa]

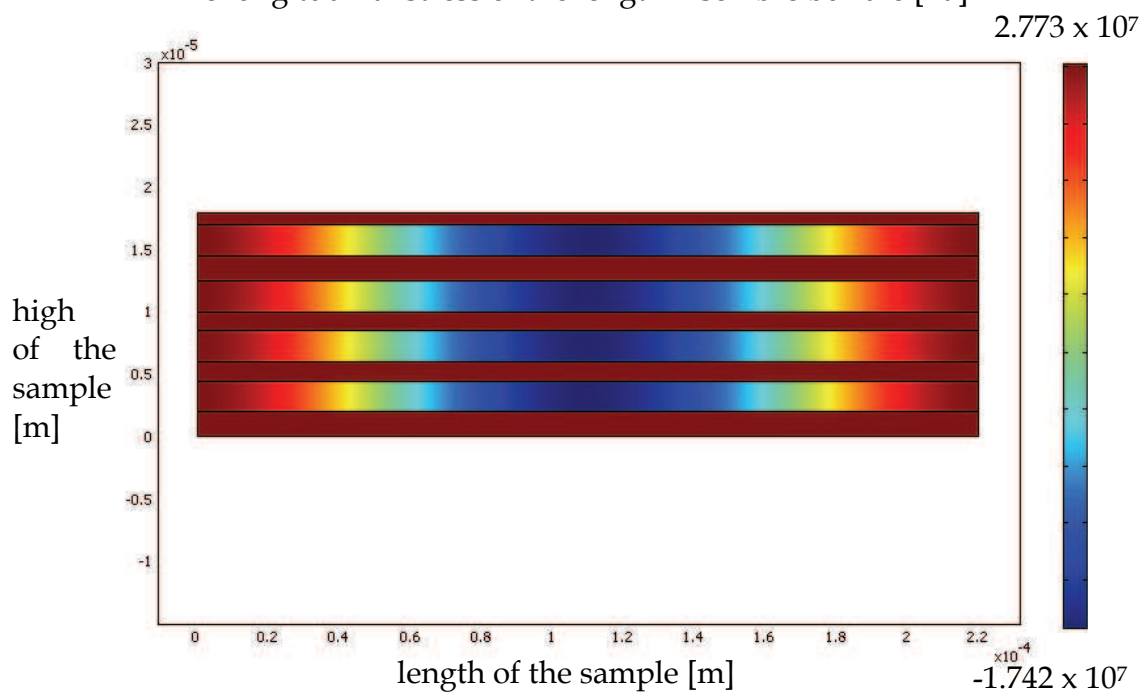

Figure 19. Longitudinal stress of the lengthwise fibre bundle 
The longitudinal strain of the lengthwise fibre bundle [-]

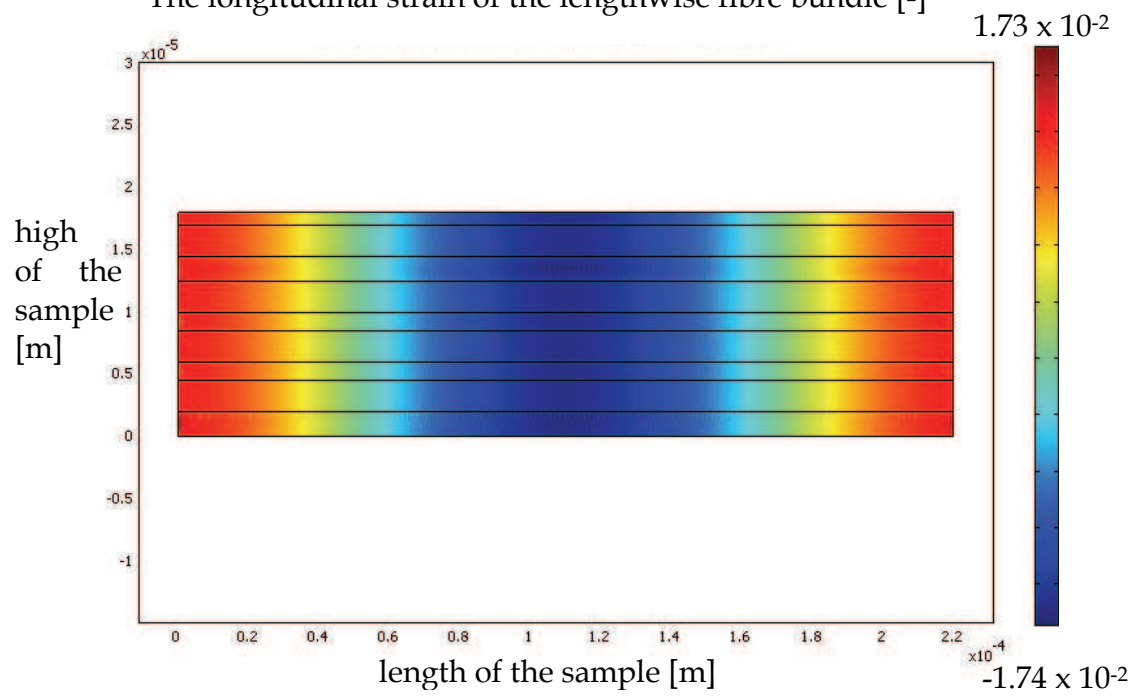

Figure 20. Longitudinal strain of the lengthwise fibre bundle

The crosswise bundle with defects has got the highest longitudinal stress in the carbon part near defects horizontal curvature (Fig. 21.). The longitudinal strain is maximal in the pores in the transversal curvature of the defects (Fig. 22.). A minimum is everywhere else. The concentration of the stress and of the strain is highly affected by the occurrence of the defects in the carbon part. The same results are shown on the Fig. 23. and Fig. 24. for the lengthwise bundle with the defects. The critical longitudinal stress is located in the carbon part and longitudinal strain is concentrated in the pores. A conclusion could be set that the carbon part carries stress and the pores localize strain.

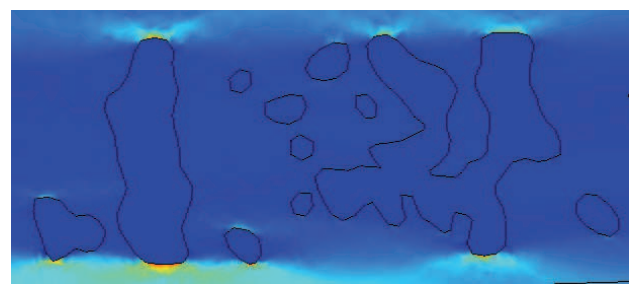

Figure 21. Longitudinal stress - crosswise bundle with defects

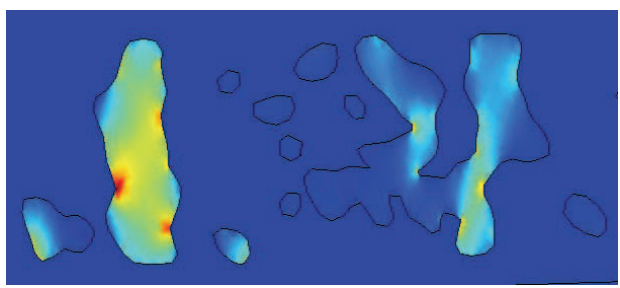

Figure 22. Longitudinal strain - crosswise bundle with defects 


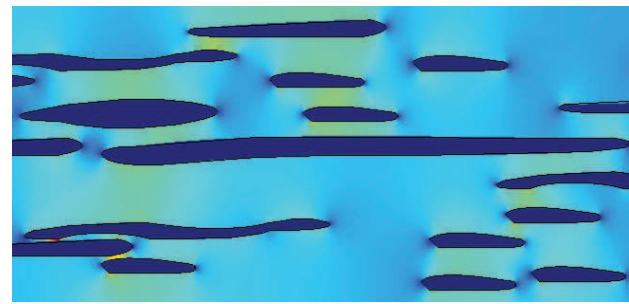

Figure 23. Longitudinal stress - lengthwise bundle with defects

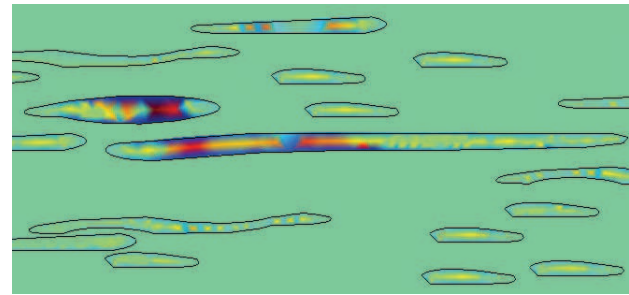

Figure 24. Longitudinal strain - lengthwise bundle with defects

The longitudinal stress for the Structural unit cell 1 (Fig. 25.) is occurred mostly in the lengthwise bundle of the reinforcement in the middle of the sample where the node point is. Minimal stress is otherwhere. The longitudinal strain in the same Structural unit cell 1 is located in the all components in the node at maximum (Fig. 26.). Stress is located in the lengthwise bundle but strain is in all material.

The longitudinal stress of the Structural unit cell $1[\mathrm{~Pa}]$

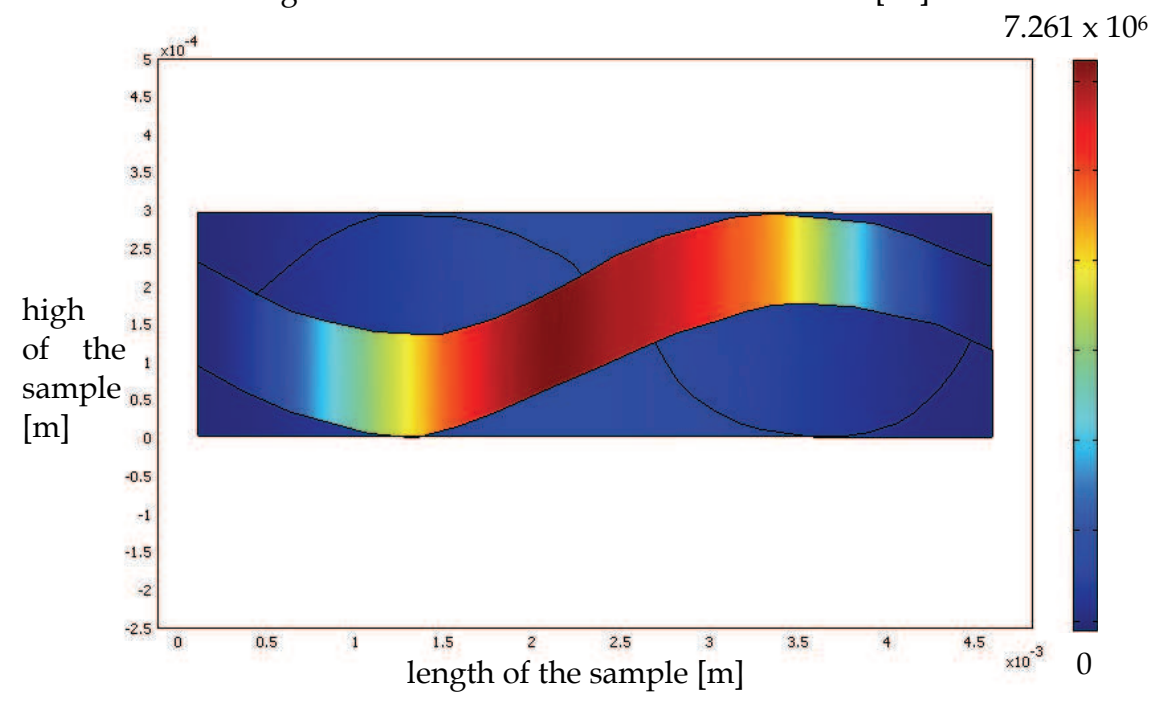

Figure 25. Longitudinal stress of the Structural unit cell 1 
Structural unit cell 2 has got the critical value of the longitudinal stress also in the lengthwise bundles (Fig. 27.). The critical loading is transferred to the side because crosswise bundles slide during processing. On the other hand the strain is maximal in the defects (Fig. 28.). The longitudinal strain in Structural unit cell 3 is also localised in the pores (Fig. 30.). The Structural unit cell 3 has got more balanced loading for the stress properties than others. The longitudinal stress is high here but not really critical.

The stress is located mostly in the lengthwise bundles in the Structural unit cells as general. The strain is the highest in all materials where defects are not but where defects were occurred strain in concentrated in the pores.

Laminas 1, 2, 3 have got the highest stress and strain in the node point and in the surrounded area. The lamina is combined from bricks with the same parameters so these results are expected.

The longitudinal strain of the Structural unit cell $1[-]$

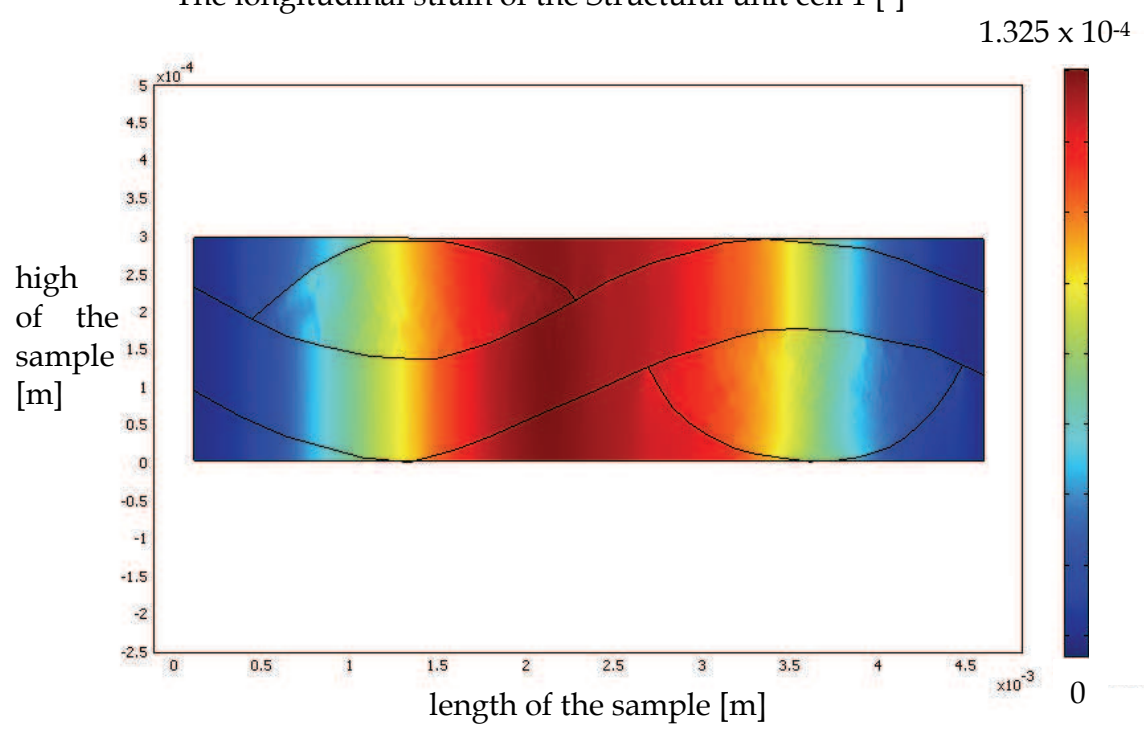

Figure 26. Longitudinal strain of the Structural unit cell 1

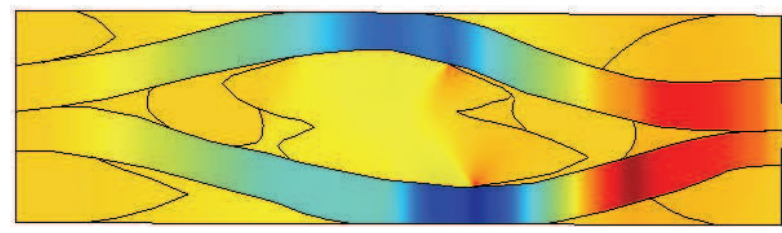

Figure 27. Longitudinal stress of the Structural unit cell 2

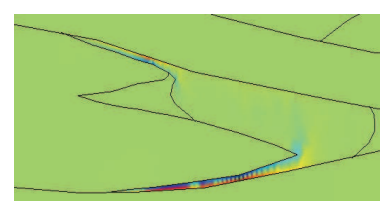

Figure 28. Longitudinal strain of the Structural unit cell 2 


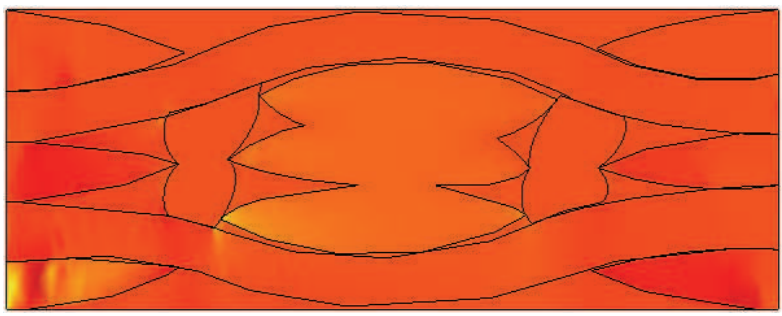

Figure 29. Longitudinal stress of the Structural unit cell 3

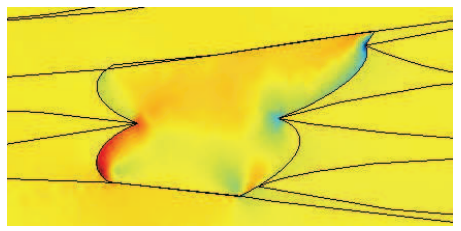

Figure 30. Longitudinal strain of the Structural unit cell 3

The longitudinal stress of the whole composite structure [Pa]

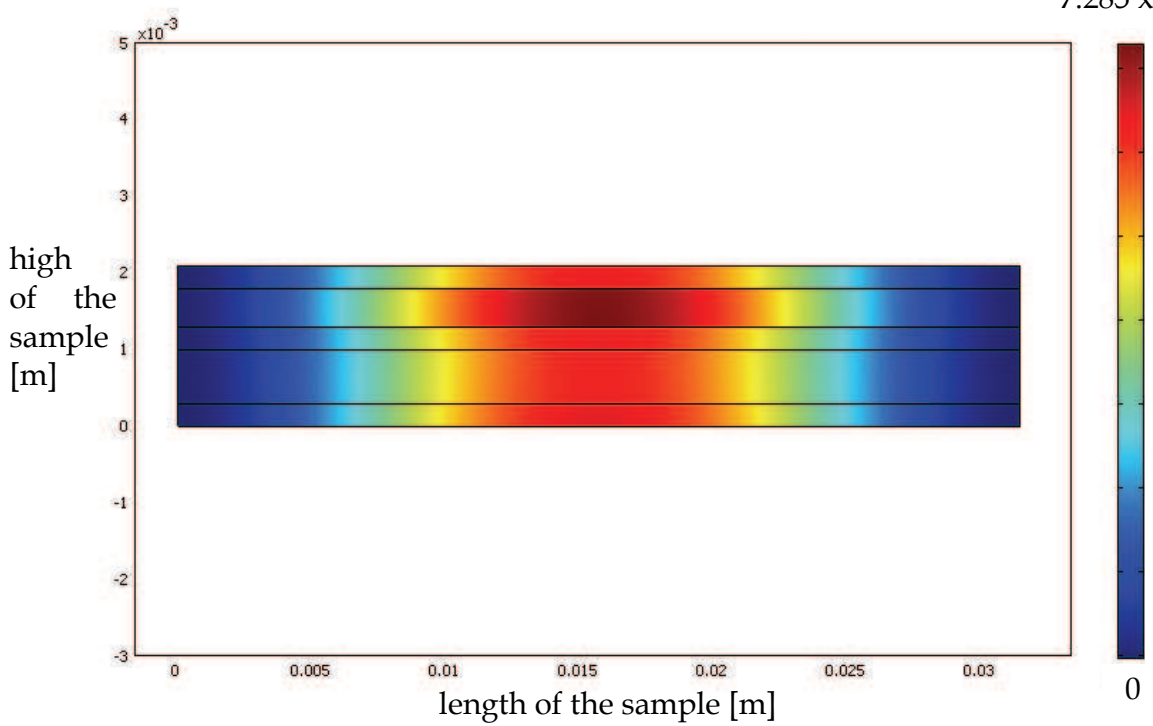

Figure 31. Longitudinal stress of the whole composite structure

The whole composite combined from laminas has got longitudinal stress the highest in the middle of the sample similarly like single lamina (Fig. 31.). The higher impact goes farther for lamina which it has got higher longitudinal stress from the previous single testing. The 
longitudinal strain for composite is also maximal in the middle (Fig. 32.). But impact is the same no matter which lamina it is.

The longitudinal strain of the whole composite structure [-]

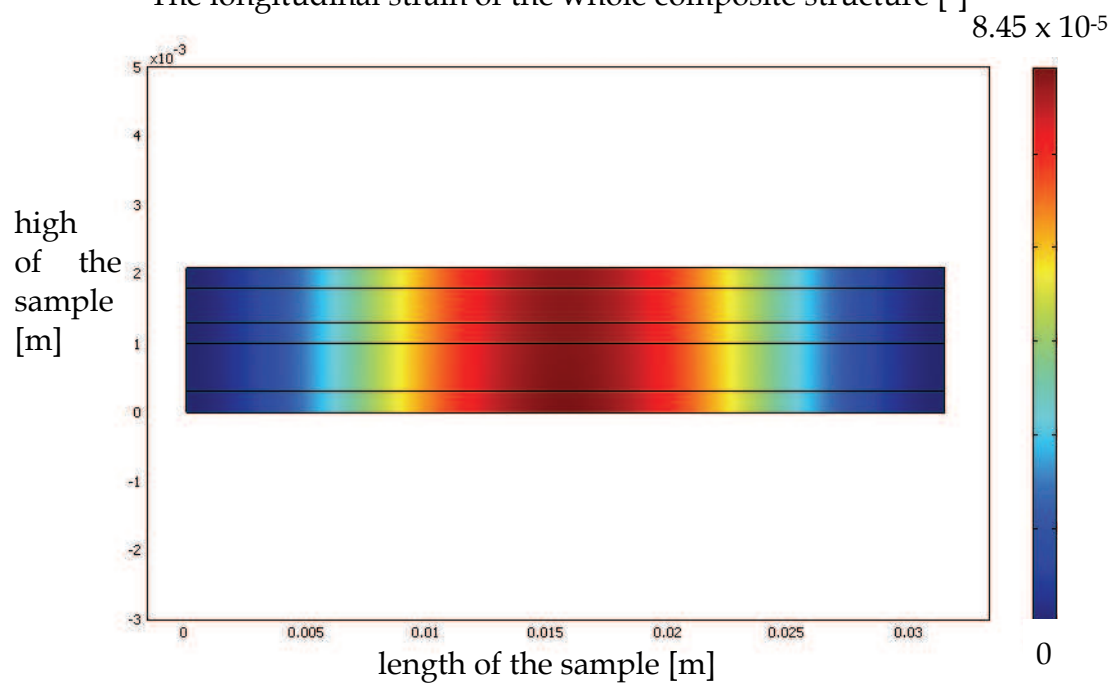

Figure 32. Longitudinal strain of the whole composite structure

\subsection{Simulation and experimental comparison}

The experiment was measured at Department of Structure and Mechanics of Rocks of Science Academy of the Czech Republic. Composite with the same properties as simulation model was prepared in directions of the warp, the weft and in the $\pm 45^{\circ}$ angle from the warp. The results are used for the in-plane discussion between simulation and experimental data on the following figures. All is completed with computed axial impact from equations in subchapter 2.1. The warp longitudinal modulus and shear modulus from simulation and experiment were input for equations completed with various angle $\delta$ in-plane of reinforcing fabric.

Table 4. shows results from experiment and simulation. The longitudinal modulus from simulation agrees with the experimental longitudinal modulus good. The simulation is a bit lower but it is still near to the hundreds of GPa. The shear modules are nearly the same for experiment and simulation.

The longitudinal modulus from simulation is a smaller than experimental only in the warp and weft direction, see Fig. 33. Longitudinal modulus in from the computation is nearly the same in $45^{\circ}$ from the warp direction. Calculation is in $45^{\circ}$ angle from the warp is same not only for experiment and simulation, but validity of equation is confirmed with comparison of measured experimental longitudinal modulus in $45^{\circ}$ which is also the same. Loading transformation in equation agree for all longitudinal modules. 


\begin{tabular}{|c|c|c|c|}
\hline & $\begin{array}{c}\text { Longitudinal } \\
\text { modulus }[\mathrm{MPa}] \\
\mathrm{E}_{\mathrm{x}}=\sigma_{\mathrm{x}} / \varepsilon_{\mathrm{x}}\end{array}$ & $\begin{array}{c}\text { Transversal } \\
\text { modulus }[\mathrm{MPa}] \\
\mathrm{E}_{\mathrm{y}}=\sigma_{\mathrm{y}} / \varepsilon_{\mathrm{y}}\end{array}$ & $\begin{array}{c}\text { Shear modulus } \\
{[\mathrm{MPa}]} \\
\mathrm{G}_{\mathrm{xy}}=\sigma_{\mathrm{xy}} / \varepsilon_{\mathrm{xy}}\end{array}$ \\
\hline $\begin{array}{c}\text { Whole composite structure } \\
\text { from simulation }\end{array}$ & $\mathbf{8 6 2 6 4}$ & 617 & 7340 \\
\hline $\begin{array}{c}\text { Composite from } \\
\text { experiment - warp } \\
\text { direction }\end{array}$ & $\mathbf{1 0 3 0 0 0}$ & - & 7630 \\
\hline $\begin{array}{c}\text { Composite from } \\
\text { experiment - } \\
45^{\circ} \text { to the warp direction }\end{array}$ & 25000 & - & 54000 \\
\hline $\begin{array}{c}\text { Composite from } \\
\text { experiment - weft } \\
\text { direction }\end{array}$ & 108000 & - & 7550 \\
\hline $\begin{array}{c}\text { Composite from } \\
\text { experiment - } \\
\text { to the warp direction }\end{array}$ & 24000 & - & 50000 \\
\hline
\end{tabular}

Table 4. Simulation and experimental elastic modules

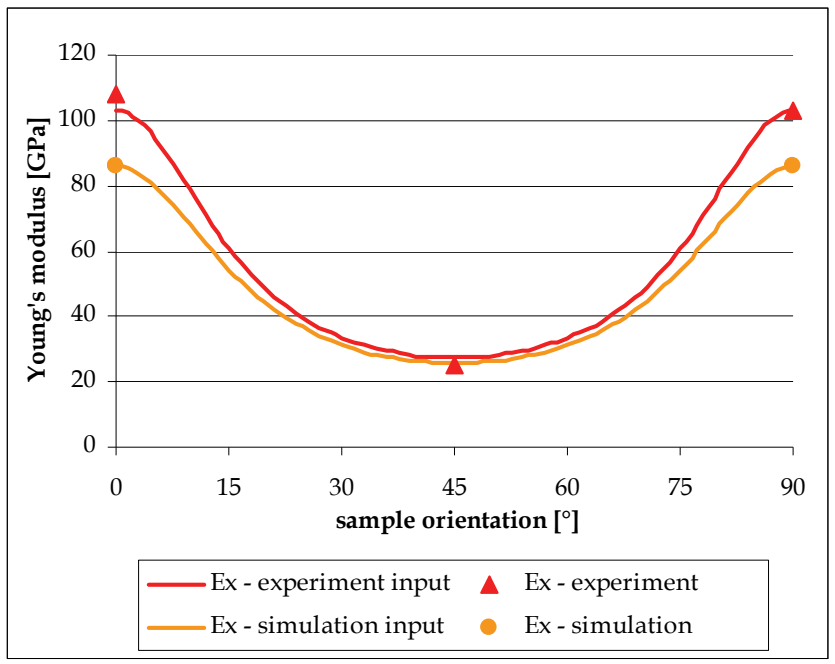

Figure 33. Longitudinal modulus from experiment and simulation

The shear modulus is the same in warp and weft direction for both comparised cases, see Fig. 34. The shear modules are different in the $45^{\circ}$ from the warp. The experimental measured shear modulus is the highest. The computed shear modulus from experiment is in the middle. The computed shear modulus from simulation is the lowest. The equation prediction is not completely the same as an experiment but results are good anyway. The shear modulus from computation gives relevant data as a critical value with margin.

On Fig. 35. is a visualisation of whole in-plane loading of longitudinal and transversal modules. The previous discussion is still valid. More, the longitudinal modulus goes in different trend than the shear modulus for both, experiment and simulation. 


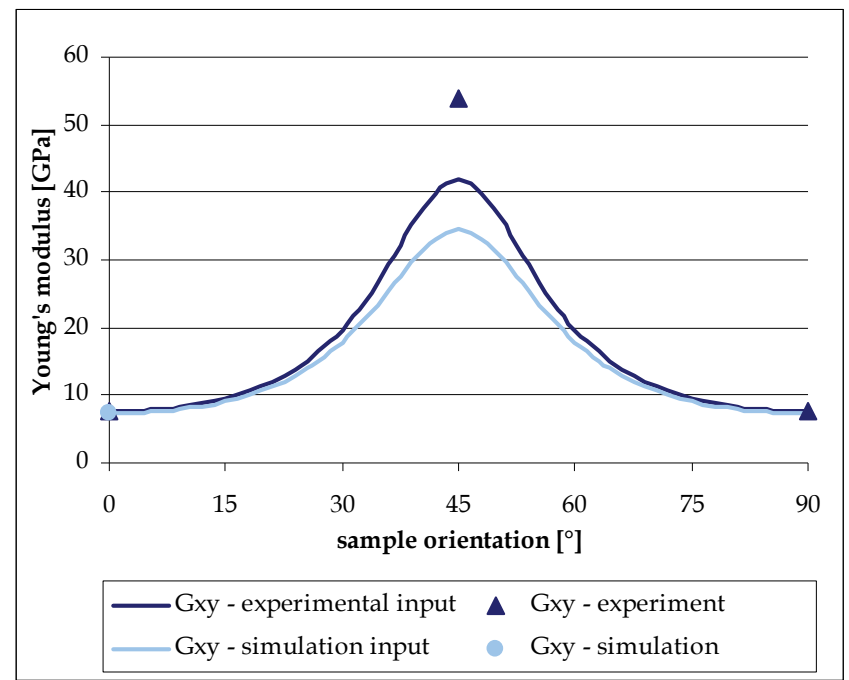

Figure 34. Shear modulus from experiment and simulation

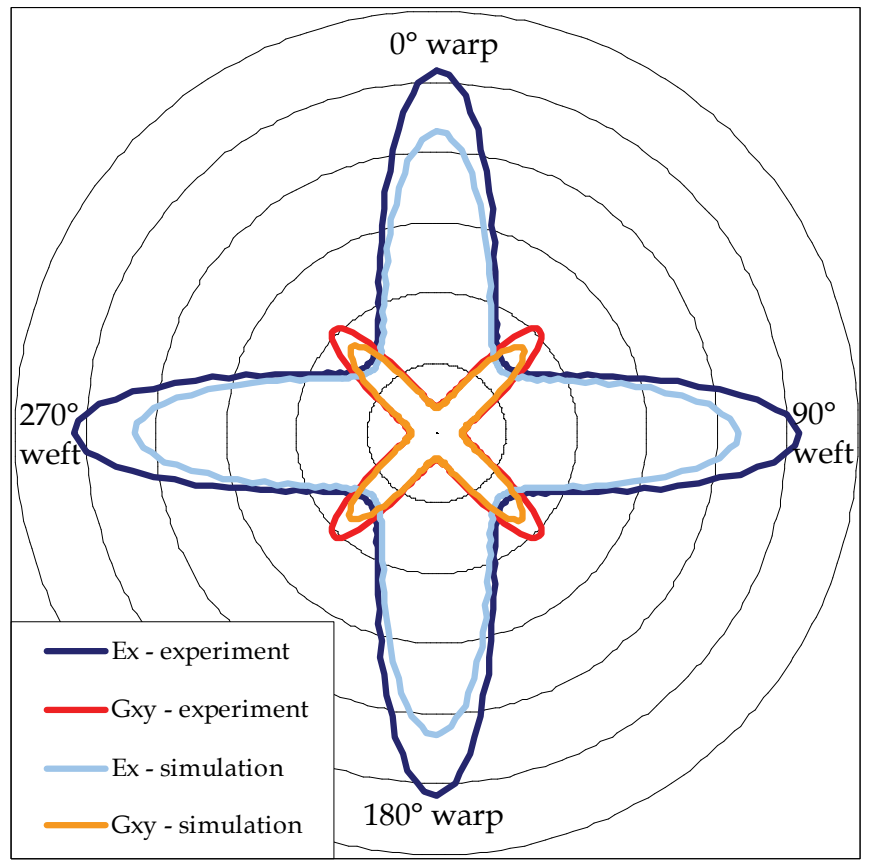

Figure 35. In-plane comparison of experiment and simulation 


\section{Conclusion}

The conclusion from the previous pages follows as estimation between the experiment and the simulation of elastic properties of the carbon/carbon composite with the plain weave reinforcement. The non-destructive testing is widely used for evaluation of the composites. The brittle carbon/carbon composite is necessary to be tested with the non-destructive methods because critical loading is not occurred with plastic deformation. Simulations with the finite element method are fast and precise same as a resonant oscillation experiment. Both methods were compared here. Experiment was tested at Department of Structure and Mechanics of Rocks of Science Academy of the Czech Republic and was used as a special comparing property for the multi-scale simulation. The commercial software Comsol Multiphysics $^{\mathrm{TM}}$ was used for calculation with proper determination of the material properties.

The simulation and experiment correlate well for longitudinal modulus of the whole composite in all directions in the in-plane of the reinforcement. The shear modules embody also good agreement between the simulation and the experimental values. Longitudinal modules go opposite way than the shear modules in both cases. The theory agrees well for it. Where warp and weft reinforce composite greatly, shear is not possible to expand. Sliding between warp and weft bundles results the higher shear modules in the $45^{\circ}$ angle from the warp direction.

The most influencing factor for the elastic properties is an amount of the lengthwise bundles for the longitudinal modulus. The position of the crosswise bundles with the matrix properties influences the shear modulus. The transversal modulus is mostly affected by the presence of the defects. Defects work upon all others modulus anyway.

Presented study affords two-dimensional multi-scale model with the good match for the testing of the real composites. The simulation was adapted well for the real composite. Combination of the multi-scale and the finite element simulation provide highly relevant data of the elastic modules which is confirmed by the used experiment.

Eigenfrequency helps to evaluate properties in longitudinal and also in the transversal directions for material with an orthotropic properties. More directions are offered to the evaluation and not only isotropic structure is possible to be used. It is an advantage of the experiment. The disadvantage it is possible testing of a thin sample body only. Some more advanced sample preparing should be done in the future for making thin plates in different directions of the composite especially for the direction transversely to the reinforcment.

The simulation with the multi-scale modelling is necessary to evaluate precise input values for the lowest scale. Here it is not problem with the fibre testing. Many methods are used and suitable. The matrix properties are more complicated to obtain. Testing of the matrix alone is a problem still and it should be solved soon.

Previous non-destructive testing is possible to use for any material with the similar structure and the same prepreg technology. If geometry models on the Structural unit cell scale are adapted, different technology should be evaluated with the same procedure too.

Both methods presented here, the experiment of resonant oscillations and the finite element simulation, are good instrument together for the testing of the elastic properties and preparing of the new composites with varied structure or material properties. 


\section{References}

Agarwal, B.D.; Broutman, L.J. (1987). Fibre composites. (Czech translation), SNTL, DT 531.8:677.499.004.12, Prague, CR

Berthelot, J.-M. (1999). Composite Materials. Mechanical Behavior and Structural Analysis. Springer-Verlag, ISBN 0-387-98426-7, New York, USA

Bogdanovich, A.E.; Pastore, C.M. (1996). Mechanics of textile laminated composites. Chapman and Hall, ISBN 041261150 3, London, UK

Brepta, R. (1997). Stress waves and beat effect in linear elastic and viscoelastic environment. Lenam, s.r.o. Liberec, ISBN 80-7083-228-2, Liberec, CR

Brepta, R.; Půst, L.; Turek, F. (1994). Oscillation mechanics. (In Czech), Technical guide 71, Sobotáles, ISBN 80-901684-8-5, Prague, CR

Cheby, S.H.; Hwu, CH. (2006). On-line measurement of material properties for composite wing structures. Composites Science and Technology, Volume 66, Issues 7-8, page numbers (1001-1009)

Composite authors (2002). Introduction to Nondestructive Testing. Interent pages of organisation: The Collaboration for NDT Education. http://www.ndted.org/GeneralResources/IntroToNDT/GenIntroNDT.htm

Composite authors (2007). NDT Applications and Limitations, NDT Encyclopedia of nondestructuive testing, NDT net. http:/ / www.ndt.net/news/files/4556.php

Černý, M. (2000). Evaluation of elastic constants of orthotropy material in state of beams and tubes. Dissertation thesis, CTU, Prague, CR

D'Amato, E. (2001) Finite Element Modeling of Textile Composites. Composite Structures, Elsevier, No. 54, page numbers (467-475)

Diederichs, R. (2007). Internet pages about NDT, Available from Wikipedia NDT Encyclopedia. http://www.ndt.net/ndtaz/ndtaz.php

Fitzer, E.; Manocha, L.M. (1998). Carbon reinforcement and Carbon-Carbon Composites. Springer -Verlag, ISBN 3-540-62933-5 Berlin, Germany

Hokr, M. (2006). Application of computer modelling. (In Czech), Study material, Technical University of Liberec, Liberec, CR

Ivanov, S.; Ivanov, D.; Lomov, S.; Verpoest, I. (2007) Modelling of mechanical behaviour of textile glass-polypropylene composite. CD Proceedings of BEM-FEM Conference, St.Petersburg, Russia, 09/2007, Catholic University of Leuven, Leuven

Kühn Gb.R. (2007) Mesoscopic resolution of plain-weave. Internet pages: Fraunhofer Institute for High-Speed Dynamics, Ernst-Mach-Institut (EMI), Freiburg, Germany, http://www.emi.fraunhofer.de/EN/ResearchFieldsAndContacts/ProjectExample s/WovenFabrics.asp

LaPlante, G.; et al. (2005). Detection of water ingress in composite sandwich structures: a magnetic resonance approach, NDT and E International, Volume 38, Issue 6, page numbers (501-507)

Laš, V. (2004). Mechanics of composite materials. West Bohemia University of Plzeň, ISBN 807043-273-X, Plzeň, CR

Lomov, S.V.; et al. (2001). Textile composites: modelling strategies. Composites Part A: applied science and manufacturing, Elsevier Science Ltd., page numbers (1379-1394)

Lomov, S.V. (2007). Virtual textile composites software WiseTex: Integration with micromechanical, permeability and structural analysis. Catholic University of Leuven, Leuven, Belgium, 2007 
Lomov, S.V.; et al. (2007). Meso-FE modelling of textile composites: road map, data flow and algorithms. CD Proceedings of International conference ICCM-15, Kyoto, Japan

Marvalová, B. (2000). Determination of effective mechanical properties of plain weave reinforcement composites. (In Czech), Inaugural dissertation, TU v Liberci, Liberec, CR

Miravete, A. (2000). 3-D textile reinforcements in composite materials. Book of contributors. Woodhead Publishing Ltd Cambridge England and CRC Press, ISBN 1-85573-3765, Cambridge, UK

Puchegger, S. el.al. (2003) Experimental validation of the shear correction factor. Letter to editor, Journal of Sound and Vibration. No. 261, page numbers (177-184)

Reddy, J.N. (2006). An Introduction to the Finite Element Metod. Third Edition, Mc Graw-Hill Higher Education, ISBN 0-07-246685-5, New York, USA

Savage, G. (1993). Carbon-Carbon Composites. Chapman and Hall, ISBN 0-080-43716-6, London, UK

Skoček, J.; Zeman, J.; Šejnoha, M. (2005). On determination of periodic unit cell for plain weave fabric composites: Geometrical modelling of real world materials. Engineering Mechanics, CTU, Prague, CR

Stříž, B. (2002). Textile Mechanics II. Application of continuum mechanics. Technical University of Liberec, Liberec, CR

Šejnoha M. (2007). Homogenisation of heterogeneous materials - similarity between textile reinforcement and historical masonry constructions. Lecture for Centre of quality and reliability of manufacturing, Technical University of Liberec, Liberec, CR

Tomková, B. (2005). Blending rules. 10. lecture for lesson Composite with textile reinforcement, Study material, Technical University of Liberec, Liberec, CR

Tomková, B. (2006). Modelling of Thermophysical Properties of Woven Composites. Dissertation thesis, Technical University of Liberec, Liberec, CR

Vinson, J.R.; Chou T.W. (1975). Composite materials and their use in the structure. Applied science publishers Ltd., London, UK

Vozková, P. (2007). Elastic Properties of Woven Composites. CD Proceedings of the Conference 15th Annual International Conference on Composites/Nano Engineering, Haikou, Hainan Island, China, 08/2007, University of New Orleans, New Orleans

Žaloudková, M. (2006). Porosity determination of C/C composites with image analysis and correlation with mechanical properties. (In Czech), Dissertation thesis, Technical University of Liberec, Liberec, CR 


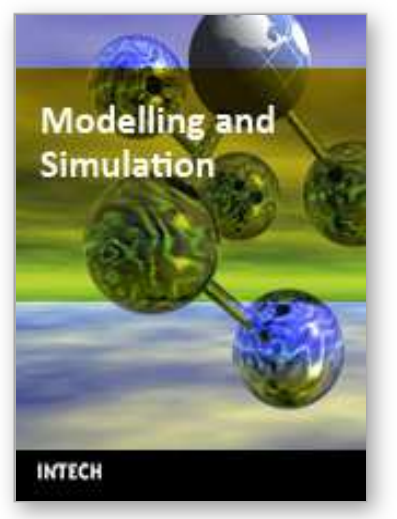

\author{
Modelling and Simulation \\ Edited by Giuseppe Petrone and Giuliano Cammarata
}

ISBN 978-3-902613-25-7

Hard cover, 688 pages

Publisher I-Tech Education and Publishing

Published online 01, June, 2008

Published in print edition June, 2008

This book collects original and innovative research studies concerning modeling and simulation of physical systems in a very wide range of applications, encompassing micro-electro-mechanical systems, measurement instrumentations, catalytic reactors, biomechanical applications, biological and chemical sensors, magnetosensitive materials, silicon photonic devices, electronic devices, optical fibers, electro-microfluidic systems, composite materials, fuel cells, indoor air-conditioning systems, active magnetic levitation systems and more. Some of the most recent numerical techniques, as well as some of the software among the most accurate and sophisticated in treating complex systems, are applied in order to exhaustively contribute in knowledge advances.

\title{
How to reference
}

In order to correctly reference this scholarly work, feel free to copy and paste the following:

Pavla Vozkova (2008). Elastic Modulus FEM Modelling of the Layered Woven Composite Material, Modelling and Simulation, Giuseppe Petrone and Giuliano Cammarata (Ed.), ISBN: 978-3-902613-25-7, InTech, Available from:

http://www.intechopen.com/books/modelling_and_simulation/elastic_modulus_fem_modelling_of_the_layered_ woven_composite_material

\section{INTECH}

open science | open minds

\author{
InTech Europe \\ University Campus STeP Ri \\ Slavka Krautzeka 83/A \\ 51000 Rijeka, Croatia \\ Phone: +385 (51) 770447 \\ Fax: +385 (51) 686166 \\ www.intechopen.com
}

\author{
InTech China \\ Unit 405, Office Block, Hotel Equatorial Shanghai \\ No.65, Yan An Road (West), Shanghai, 200040, China \\ 中国上海市延安西路65号上海国际贵都大饭店办公楼 405 单元 \\ Phone: +86-21-62489820 \\ Fax: +86-21-62489821
}


(C) 2008 The Author(s). Licensee IntechOpen. This chapter is distributed under the terms of the Creative Commons Attribution-NonCommercialShareAlike-3.0 License, which permits use, distribution and reproduction for non-commercial purposes, provided the original is properly cited and derivative works building on this content are distributed under the same license. 